\title{
Cardiac mass in glucocorticoid-hypertensive rats with and without circulating adrenaline
}

\author{
JAMES F BURRIS, BERNARD WAEBER, AND HANS R BRUNNER \\ From the Division of Nephrology and Hypertension, Centre Hospitalier Universitaire, Lausanne, Switzerland
}

SUMMARY There is evidence that catecholamines may promote the development of cardiac hypertrophy in hypertension. To test the hypothesis that adrenaline directly determines left ventricular mass, normotensive Wistar rats were made adrenaline-deficient by adrenalectomy and hypertensive by administration of glucocorticoid. Blood pressure, heart rate, and body weight of the adrenalectomised group were not significantly different from a glucocorticoid treated control group with intact adrenals. Heart weight was significantly lower in the adrenalectomised rats, but this difference disappeared when heart weight was adjusted for body weight. It appears therefore that the presence or absence of adrenaline does not significantly affect cardiac mass in the presence of hypertension in this animal model.

Sustained arterial hypertension frequently results in the development of myocardial hypertrophy. The increased pressure itself, by increasing ventricular afterload and wall tension, is thought to be the principal stimulus to left ventricular hypertrophy. ${ }^{1.2}$ However, there are circumstances in which cardiac hypertrophy develops, progresses, or regresses without accompanying appropriate changes in blood pressure, suggesting that other factors in addition to blood pressure per se may be involved in the hypertrophic process. $^{2}$ There are several lines of evidence suggesting that beta adrenoceptor stimulation by catecholamines plays a trophic role in the genesis of myocardial hypertrophy. ${ }^{2-10}$ Current work in this laboratory with a model of glucocorticoid-induced hypertension in Wistar rats ${ }^{11}$ offered an opportunity to investigate whether cardiac mass is smaller in the absence of circulating adrenaline when compared with equally hypertensive animals able to normally release adrenaline from the adrenals.

* Send Correspondence and reprint requests to: Hans $\mathrm{R}$ Brunner, MD, Dept of Medicine, C.H.U.V., 1011 Lausanne, Switzerland.

Key terms: adrenaline; adrenalectomy; cardiac hypertrophy; glucocorticoid induced hypertension.

\section{Methods}

Male normotensive Wistar rats with initial weights of approximately $250 \mathrm{~g}$ were biadrenalectomised under ether anaesthesia and made hypertensive with methylprednisolone (Depo-Medrol ${ }^{\circledR} 40 \mathrm{mg} \cdot \mathrm{ml}^{-1}$, Upjohn) $20 \mathrm{mg} \cdot \mathrm{kg}^{-1}$ subcutaneously once weekly for 2 weeks. Deoxycorticosterone pivalate (Percorten-M ${ }^{\circledR}$ $25 \mathrm{mg} \cdot \mathrm{ml}^{-1}$, Ciba-Geigy) $10 \mathrm{mg} \cdot \mathrm{kg}^{-1}$ was also given subcutaneously once weekly to prevent mineralocorticoid deficiency. Sham operated controls prepared by bilateral flank incisions and direct visualisation of the adrenal glands received the same steroid treatments. All rats had free access to tap water and regular rat chow containing $0.113 \mathrm{mmol} \cdot \mathrm{g}^{-1}$ of sodium (Indulab ${ }^{\circledR}$, Buchs, Switzerland). As expected from previous experiments, ${ }^{11}, 12$ all rats lost weight between the initial surgery and the day of experiment due to the catabolic effect of the administered glucocorticoids.

The animals were used for experiments 12 to 16 days after initial surgery. Under light ether anaesthesia a PE-50 plastic catheter was implanted in the right iliac artery and a PE- 10 catheter in the right iliac vein. Rats were then semi-restrained in individual plexiglass tubes and allowed to recover from the anaesthesia and surgery for 90 min prior to experiments. Mean blood 
TABLE Characteristics of adrenalectomised and sham-operated rats with glucocorticoid-induced hypertension.

\begin{tabular}{llllll}
\hline & $\begin{array}{l}\text { Mean blood } \\
\text { pressure } \\
(\mathrm{mmHg})\end{array}$ & $\begin{array}{l}\text { Heart } \\
\text { rate } \\
\left(\text { beats } \cdot \mathrm{min}^{-1}\right)\end{array}$ & $\begin{array}{l}\text { Body } \\
\text { weight } \\
(\mathrm{g})\end{array}$ & $\begin{array}{l}\text { Heart } \\
\text { weight } \\
(\mathrm{mg})\end{array}$ & $\begin{array}{l}\text { Heart weight } \\
\text { Body weight } \\
\left(\mathrm{mg} \cdot \mathrm{g}^{-1}\right)\end{array}$ \\
\hline $\begin{array}{l}\text { Adrenalectomised } \\
\mathrm{n}=29\end{array}$ & $146 \pm 2$ & $456 \pm 8$ & $205 \pm 3$ & $660 \pm 13$ & $3.23 \pm 0.07$ \\
$\begin{array}{l}\text { Sham-operated } \\
\mathrm{n}=31\end{array}$ & $144 \pm 2$ & $476 \pm 11$ & $214 \pm 3$ & $720 \pm 15$ & $3.36 \pm 0.07$ \\
& $\mathrm{NS}$ & $\mathrm{NS}$ & $\mathrm{NS}$ & $\mathrm{p}=0.004$ & $\mathrm{NS}$ \\
\hline
\end{tabular}

Results expressed as mean $\pm \mathrm{SEM}, \mathrm{NS}=$ not statistically significant

pressure and heart rate were recorded directly through the arterial catheter using a pressure transducer (Bell and Howell No. 4-327-I, Pasadena, California) connected to an electrogalvanometer (Philips 2000, Eindhoven, Netherland) and recorded on a Manarp 150 light-sensitive oscillograph (Electric Institute Limited, London). There were 29 animals in the adrenalectomised and 31 in the sham-operated group. After death the heart was removed, the atria and great vessels were excised, the ventricles were opened so all surfaces could be blotted free of blood, and the ventricles were weighed.

Results are expressed as mean \pm standard error of the mean (mean $\pm S E M$ ) for each group. For the statistical evaluation of differences among groups a Student's $t$ test for unpaired data was used.

\section{Results}

There was no significant difference between adrenalectomised and sham-operated groups of rats in intra-arterial mean blood pressure, heart rate, or body weight on the day of the experiment (table).

Heart weight of the adrenaline-deficient adrenalectomised group of rats was significantly lower than that of the sham-operated rats. However, the heart weight to body weight ratio was comparable for both groups. These results are also shown in the table.

\section{Discussion}

Several recent studies have examined the role of the adrenal glands in the development of cardiac hypertrophy in various animal models of hypertension. Womble and co-workers have shown that elevation of adrenaline in plasma parallels the development of cardiac hypertrophy in dogs with surgically induced coarctation of the aorta ${ }^{6}$ and that adrenal medullary cholinergic denervation not only prevents development of left ventricular hypertrophy but results in a decreased heart weight/body weight ratio compared to controls. ${ }^{7}$ Noradrenaline levels were not significantly different in any of the experimental groups. The authors implicated adrenaline as the specific hormone regulating cardiac mass. ${ }^{7}$ It would of course, be difficult to understand why a circulating factor could exclusively lead to hypertrophy of the left heart as it was observed in this model. These authors did not report the blood pressures or heart rates of any of their experimental or control groups of dogs. In other studies it has been shown that the myocardial hypertrophy which develops in male Sprague-Dawley rats after construction of the abdominal aorta can be prevented to a great extent by bilaterally adrenalectomising the animals prior to constriction of the aorta. ${ }^{8}$ Removal of only the adrenal medullae failed to prevent the hypertrophy, suggesting that the adrenalcortical steroids, rather than adrenaline, are crucial to the development of cardiac hypertrophy in this model. ${ }^{8}$ Blood pressures and heart rates of the adrenalectomised and medullectomised rats were lower than those of the untreated controls in these experiments, and there were also differences in these parameters between the rats with aortic coarctation and the sham-operated controls. Bilateral adrenal demedullation alone or in combination with chemical sympathectomy also failed to alter cardiac hypertrophy in SHR. ${ }^{9}$ However, relative myofibril volume decreased in the hearts of these rats, suggesting that catecholamines are involved in the disproportionate growth of myofibrils characteristic of cardiac hypertrophy evoked by pressure-overload. ${ }^{9}$ Systolic blood pressure in SHR was reduced by bilateral adrenal demedullation alone or in combination with chemical sympathectomy in comparison to sham control SHR in these experiments, and blood pressure was substantially lower in all Wistar-Kyoto control groups than in the SHR groups. Heart rates of the different experimental groups were not reported.

In the experiments reported here, Wistar rats were adrenalectomised to render them adrenaline-deficient and made hypertensive with exogenous glucocorticoid. Small amounts of mineralocorticoid were administered to prevent mineralocorticoid deficiency. This procedure virtually eliminates 
circulating adrenaline whereas plasma noradrenaline levels are not statistically different compared with those of sham-operated control rats. ${ }^{11}$ In contrast to the experiments cited above, the adrenalectomised rats and their sham-operated controls in this experiment had equal blood pressure and heart rates after these manipulations, so any observed differences in cardiac weight cannot be attributed to differences in these factors. The ratio of heart weight to body weight was slightly lower in the adrenaline-deficient rats than in the controls, but this difference was not statistically significant. This finding suggests that circulating adrenaline does not play a major role in regulating cardiac mass in rats with glucocorticoid-induced hypertension. In view of the results obtained by Nichols and his associates, ${ }^{8}$ the possibility must be entertained that the adrenal cortical steroids administered to all of our rats sustained the development of cardiac mass to a similar extent, whether circulating adrenaline was present or absent. Alternatively, it is possible that the lack of difference in cardiac mass between the two study groups is due to a tropic effect of noradrenaline released by terminal nerve endings. 3,4

In summary, the results of this study suggest that presence or absence of adrenaline does not significantly affect the development of cardiac mass in the presence of glucocorticoid-induced hypertension in the Wistar rat.

This research was supported in part by grants from the Cardiovascular Research Foundation, from the Swiss National Science Foundation (Nrs 3.914-0.80, $3.824-0.81$ and $3-730-0.81$ ).

\section{References}

1 Wikman-Coffelt J, Parmley WW, Mason DT. The cardiac hypertrophy process. Analysis of factors determining pathologic vs physiologic development. Circ Res pathologic vs

2 Frohlich ED, Tarazi RC. Is arterial pressure the sole factor responsible for hypertensive cardiac hypertrophy? Am J Cardiol 1979;44:959-63.

3 Östman-Smith I. Prevention of exercise-induced cardiac hypertrophy in rats by chemical sympathectomy (guanethidine treatment). Neuroscience 1976;1:497-507.

4 Laks MM. Norepinephrine - the producer of myocardial cellular hypertrophy and/or necrosis and/or fibrosis. $A m$ Heart $J$ 1977:94:394-9.

5 Pfeffer MA, Pfeffer JM, Weiss AK, Frohlich ED. Development of SHR hypertension and cardiac hypertrophy during prolonged beta-blocking therapy. Am J Physiol 1977;231:H639-43.

6 Womble JR, Haddox MK, Russell DH. Epinephrine elevation in plasma parallels canine cardiac hypertrophy. Life Sci 1978;23:1951-8

7 Womble JR, Larson DF, Copeland JG, Brown BR, Haddox MK, Russell DH. Adrenal medulla denervation prevents stress-induced epinephrine plasma elevation and cardiac hypertrophy. Life Sci 1980;27:2417-20.

8 Nichols JR, Clancy RL, Gonzalez NC. Role of adrenals on development of pressure-induced myocardial hypertrophy. Am J Physiol 1983;244:H234-8.

9 Tomanek RJ, Bhatnagar RK, Schmid P, Brody MJ. Role of catecholamines in myocardial cell hypertrophy in hypertensive rats. Am J Physiol 1982:242:H1015-21.

10 Östman-Smith 1. Cardiac sympathetic nerves as the final common pathway in the induction of adaptive cardiac hypertrophy. Clin Sci 1981:61:265-72.

11 Burris JF, Waeber B, Brunner HR. Enhanced antihypertensive effect of propranolol in the absence of circulating epinephrine. J Cardiovasc Pharmacol 1984;6:697-700

12 Krakoff LR, Selvadurai R, Sutter E. Effect of methylprednisolone upon arterial pressure and the renin-angiotensin system in the rat. Am J Physiol 1975;228:613-7. 